\title{
THE USE OF MACHINE HAMMER PEENING TECHNOLOGY FOR SMOOTHENING AND STRUCTURING OF SURFACES
}

\author{
LECHNER, C[hristoph]; BLEICHER, F[riedrich]; HABERSOHN, C[hristoph]; \\ BAUER, C[hristian] \& GOESSINGER, S[tefan]
}

\begin{abstract}
Machine Hammer Peening (MHP) poses a novel technical tool, to modify metal surfaces in a controlled manner. As part of this modification the materials surface topography can be influenced in different ways. On one hand, a surface smoothening effect up to mirror-like surfaces can be realized by the use of this technology and on the other hand it is possible to structure a surface with defined geometries. There are a number of process parameters which can be varied to influence the peening result. This paper seeks to explore the effects of several process parameters and how these parameters have to be optimized for surface smoothening of a C45E steel sample. Beside the surface smoothening effect further modifications of the resulting surface topography, depending on different process parameters, are investigated. A defined micro structuring of the surface can also be achieved by the use of peening tools with functionally shaped tips. In this case the negative form of the desired structure is machined on the tool tip and stamped on the treated surface by the well adjusted structure of the peening tool during the Machine Hammer Peening process. Examples of structured surfaces will be given in this paper.
\end{abstract}

Keywords: machine hammer peening, surface treatment, surface smoothening, surface structuring

\section{INTRODUCTION}

The Machine Hammer Peening (MHP) surface treatment technology was developed by the German company KWL (Konstruktion und Werkzeugbau Löcker) in order to replace the manual polishing procedure of workpiece surfaces by an automated process [1]. During the treatment a tool with a spherical carbide tip is used to hammer the surface of a workpiece by well directed hits. Therefore the tool is performing an oscillating movement produced by an actuator. This device can be attached to any kind of machine tool, which is providing a relative movement between the workpiece and the peening tool.

As a result of these movements single impacts arranged one after the other are cold working the material, which causes an increase of hardness of the upper surface layer. Also the induction of compressive residual stresses into the material is reported and the original process application of surface smoothening can be achieved by the choice of the right parameter setting [6].

A main application for the surface smoothening ability of Machine Hammer Peening can be found in finishing of pressing dies used in the automotive industry, like presented in [2-5]. Therefore investigations reported so far in the literature are mainly dealing with common pressing die materials like for example GGG70L, a nodular iron with spheroidised graphite nodules [5]. Also the influences of several process parameters are reported in [4], were the medium alloyed cold work steel $60 \mathrm{CrMoV} 18-5$ (1.2358) as well as the zinc alloy $\mathrm{ZnAl} 4 \mathrm{Cu} 3$ have been investigated during Machine Hammer Peening experiments.

So far there is no research reported which is dealing with the plain carbon steel C45E (1.1191) as workpiece material, which is often used for mechanical engineering and therefore of high interest for several applications.

This paper seeks to explore the surface smoothening ability of the MHP technology in terms of C45E, depending on the variation of different process parameters, within the scope of a parameter study. Furthermore the influence of varying parameters on the surface topography will be analyzed. Depending on the parameter settings different surface structures can be achieved as a result of the process. The wide spectrum of possibilities will be summarized by presenting representative examples of resulting topographies.

Another aim of this work is to analyze the feasibility of defined micro structuring using the MHP technology. A new method, based on functionally formed peening tools, which has been developed as part of this research, will be investigated and additionally results of structured aluminium alloy surfaces are presented in chapter 5 .

\section{EXPERIMENTAL SETUP}

\subsection{Machine Hammer Peening}

In the present studies an electro-magnetic actuator system (accurapuls) was used. This actuator applies an oscillation movement up to $500 \mathrm{~Hz}$ to the plunger and is based on the mechanism of moving a coil electromagnetically. Due to a sinusoidal current which is applied to the coil the plunger is pushed onto the surface and lifted back again (Lorenz force).

The actuator was attached to a C20U (Hermle) milling machine. This 5-axis machining centre is able to achieve a full 5-axis processing by combining the motions of three linear axes with those of a 360-degree rotary table mounted on a 115-degree swiveling trunnion. Fig. 1 is presenting an illustration of the applied experimental setup, which provides a high stiffness and therewith a high positioning accuracy of the plunger. 


\begin{tabular}{|l|l|c|l|}
\hline \multirow{2}{*}{ Symbol } & \multicolumn{3}{|c|}{ MHP-process parameters } \\
\cline { 2 - 4 } & Parameter & Unit & \multicolumn{1}{c|}{ Description } \\
\hline $\mathrm{D}$ & Diameter & $\mathrm{mm}$ & $\begin{array}{l}\text { Diameter of the spherical } \\
\text { plunger tip }\end{array}$ \\
\hline $\mathrm{t}$ & $\begin{array}{l}\text { Peening } \\
\text { distance }\end{array}$ & $\mathrm{mm}$ & $\begin{array}{l}\text { Distance between tip and } \\
\text { material surface }\end{array}$ \\
\hline $\mathrm{s}$ & Line pitch & $\mathrm{mm}$ & $\begin{array}{l}\text { Distance between the } \\
\text { peening lines }\end{array}$ \\
\hline $\mathrm{F}$ & Frequency & $\mathrm{Hz}$ & $\begin{array}{l}\text { Frequency of the } \\
\text { oscillation plunger } \\
\text { movement }\end{array}$ \\
\hline $\mathrm{I}$ & Intensity & $\%$ & $\begin{array}{l}\text { influencing the current } \\
\text { induced in the plunger coil }\end{array}$ \\
\hline $\mathrm{v}$ & Feed rate & $\mathrm{mm} / \mathrm{min}$ & $\begin{array}{l}\text { provided by the machine } \\
\text { tool }\end{array}$ \\
\hline $\mathrm{f}$ & $\begin{array}{l}\text { Distance } \\
\text { between } \\
\text { two hits }\end{array}$ & $\mathrm{mm}$ & determined by F and v \\
\hline
\end{tabular}

Tab. 1. MHP-process parameters

There are various process parameters which can be adjusted on the machine tool as well as on the actuator to influence the process result. The most important parameters are shown and explained in Tab. 1 and are illustrated in Fig. 1.

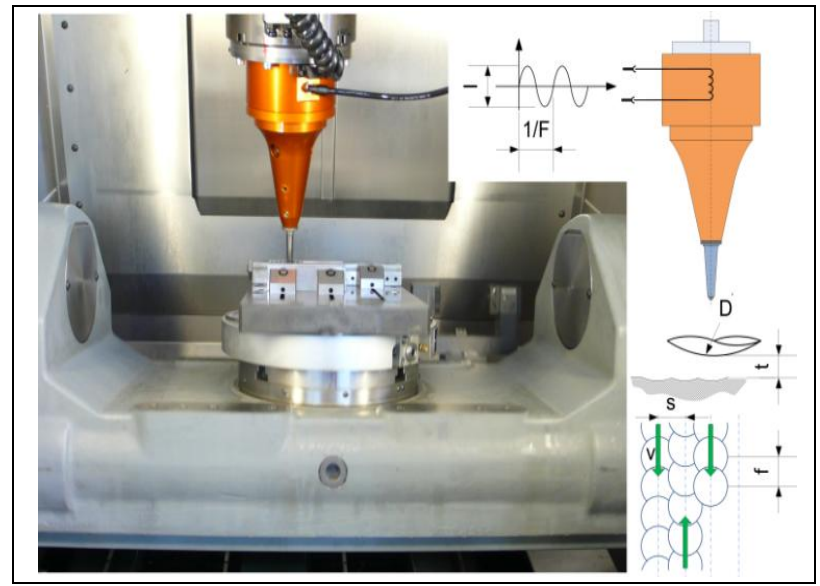

Fig. 1. Experimental setup (MHP-actuator attached to a C20U machine centre) and illustration of MHP-parameters described in Tab. 1.

\subsection{Evaluation}

In order to get a first impression, a stereomicroscope SMZ 1500 (Nikon) was used to observe the resulting surfaces. Especially in the case of defined surface micro structuring (chapter 5), this device, which covers a zoom range from $0.75 \mathrm{x}$ to $11.25 \mathrm{x}$, was well placed to assess if a variation of a specific process parameter is influencing the structuring result.

Further investigations and measurements of the realized surface topographies have been done by the use of the optical three-dimensional surface topography measurement device Infinite Focus (Alicona). Based on the operating principle of Focus-Variation a dense 3D surface representation of the measured object can be obtained by the use of this measurement system. This representation can further be analyzed in different kind of ways, like the extraction and evaluation of depth profiles.

Surface roughness measurements were made using a surface roughness tester MarSurf PS 1 (Mahr). The data, surface average roughness $R_{a}$ as well as the Ten-point mean roughness $R_{z}$, have been measured normal to and in feed direction of the peening process (peening direction). The measurements given are based on mean values of six single measurements.

\section{SURFACE SMOOTHENING}

\subsection{Approach}

A C45E (1.1191) steel sample was prepared by face milling under the use of an $\varnothing 16 \mathrm{~mm}$ end mill cutter, $\mathrm{f}_{\mathrm{t}}=0.08 \mathrm{~mm}$. After milling of the sample the thickness has been $8 \mathrm{~mm}$ and the surface roughness measurement showed the following values: $\mathrm{R}_{\mathrm{a}}=1.98 \mu \mathrm{m}, \mathrm{R}_{\mathrm{z}}=10.91 \mu \mathrm{m}$ in milling direction and $\mathrm{R}_{\mathrm{a}}=1.54 \mu \mathrm{m}, \mathrm{R}_{\mathrm{z}}=8.38 \mu \mathrm{m}$ normal to it.

During the experiment, all in all, nine test fields (square areas of side length $22 \mathrm{~mm}$ ) with different parameter settings have been hammer peened on the milled surface. The peening direction of the MHPprocess has been chosen orthogonal to the direction of the further face milling step.

Three plungers of different sphere diameter $D(6 \mathrm{~mm}$, $8 \mathrm{~mm}$ and $10 \mathrm{~mm}$ ) have been used. As a second parameter the line pitch $s$ between the peening lines has been varied and was set to the values of $0.1 \mathrm{~mm}, 0.3 \mathrm{~mm}$ and $0.5 \mathrm{~mm}$.

The feed rate $v$ was chosen, in function of the corresponding line pitch, at $1200 \mathrm{~mm} / \mathrm{min}(\mathrm{s}=0.1 \mathrm{~mm})$, $3600 \mathrm{~mm} / \mathrm{min}(\mathrm{s}=0.3 \mathrm{~mm})$ and $6000 \mathrm{~mm} / \mathrm{min}(\mathrm{s}=0.5 \mathrm{~mm})$.

This choice derives from the fact that under these feed rate values and for the peening frequency of $200 \mathrm{~Hz}$, used in this experiment, the distance $f$ between the single impacts, which can be calculated by:

$$
\mathrm{f}[\mathrm{mm}]=\frac{\mathrm{v}[\mathrm{mm} / \mathrm{min}] / 60[\mathrm{~s} / \mathrm{min}]}{\mathrm{F}[\mathrm{Hz}]}
$$

corresponds to the line pitch $s$ for the machining of each test field ( $\mathrm{f}=\mathrm{s}$ as shown in Fig. 3 ).

\subsection{Experimental results}

In comparison to the milled reference surface the roughness of the hammer peened surfaces could be decreased for nearly each parameter setting in each direction (in peening direction as well as normal to it).

Only the field treated with the smallest tool sphere diameter $(D=6 \mathrm{~mm})$ in combination with the highest line pitch value of $s=0.5 \mathrm{~mm}$ showed nearly the same roughness normal to the peening direction like before being treated by MHP.

The surface roughness values $R_{a}$ and $R_{z}$ measured on the milled reference surface and on three machine hammer peened surfaces, treated with different parameter settings, which are representing significant factor levels, are given in Fig. 2.

As it could be shown both during the experiment varied parameters, the sphere diameter $D$ as well as the line pitch $s$, are influencing the resulting surface roughness. 


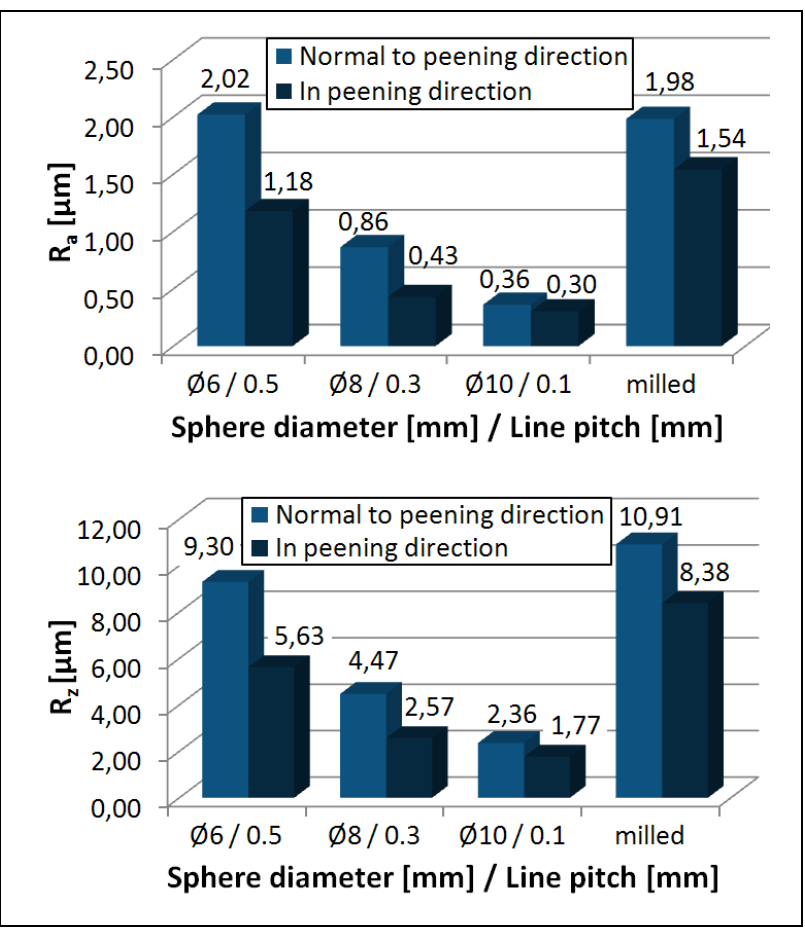

Fig. 2. Surface roughness of three hammer peened and the milled reference surface, measured normal as well as parallel to the MHP direction

It was observed, that the surface roughness decrease goes along with increasing sphere diameter $D$ and decreasing line pitch $s$.

Fig. 3 is illustrating the parameter influence by showing the roughness value $\mathrm{R}_{\mathrm{a}}$ measured normal to the peening direction depending on the respective parameter settings.

Based on this result it can be pointed out that the choice of a large sphere diameter in combination with a small line pitch and a small feed rate, therewith consequently a small distance between the single impacts of the peening tool, are beneficial for surface smoothening of the investigated C45E steel sample.

In the case of the largest used sphere diameter and the smallest distances between the impacts a mirror-like surface, shown in the lower right part of Fig. 3 was the result.

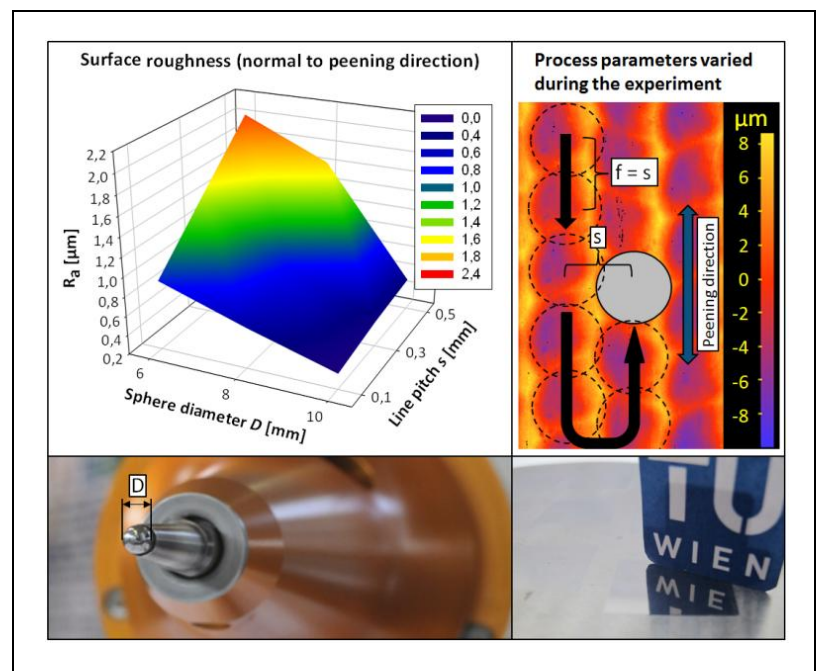

Fig. 3. Illustration of surface roughness depending on the varied process parameters: line pitch $s$ and sphere diameter $D$

\section{INFLUENCE ON SURFACE TOPOGRAPHY}

Previous work [6], which was focusing on the variation of the feed rate $v$ in the course of a one factor at a time test, demonstrated that MHP leads to numerous possibilities of variations regarding the resulting surface topography.

Additionally, in further experiments the influence of the line pitch $s$ and the peening distance $t$ have been investigated in order to optimize the technological properties of surface structuring depending on the arrangement of different process parameters.

An overview of the properties in surface structuring depending on the peening parameters will be given in this chapter.

\subsection{Approach}

A peening tool with a spherical tip of $6 \mathrm{~mm}$ diameter has been used to treat the face milled surface of $\mathrm{C} 45 \mathrm{E}$ steel samples by the use of different feed rates $v$, line pitches $s$ and peening distances $t$ in order to create different surface topographies.

For all experiments the peening frequency has been set to the value of $200 \mathrm{~Hz}$. The resulting surfaces have then been investigated by Infinite Focus (Alicona) surface topography measurements.

\subsection{Experimental results}

Depending on the arrangement of the single tool impacts, determined by the line pitch value $s$ and the distance between the hits $f$, different topographies are occurring after the MHP-process.

Fig. 4 is illustrating this wide spectrum of topographies which ranges from very smooth, mirror-like surfaces to distinct tool paths and further to single impacts. As shown, the surface topography measurements emphasize the requirement of a small impact distance (line pitch $s$, distance between hits $f$ ) for optimized surface smoothening.

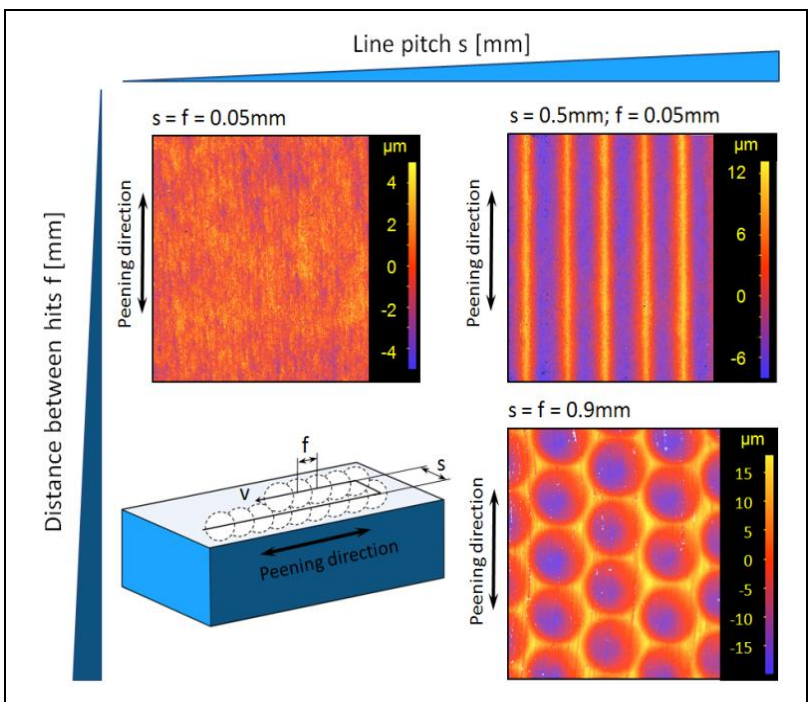

Fig. 4. Surface topography measurements of surfaces machined with different distances between the hits and line pitches between the tool paths 
If the line pitch $s$ is increased by unchanged distance $f$ between the impacts, material is mainly pushed aside of each tool path during the process. After machining the single tool path, lines are dominating the topography of the resulting surface.

If both, line pitch $s$ and distance $f$, are increased single indentations are the outcome. Thereby also the creation of patterns of circular depressions is possible.

It is likely that these systematic patterning could be used for the improvement of the tribological performance of components and has been part of further investigations.

During this experiment single impact lines have been produced by the use of a feed rate of $30000 \mathrm{~mm} / \mathrm{min}$. According to equation (1) a distance of $\mathrm{f}=2.5 \mathrm{~mm}$ between the single indentations is the result of this high feed rate (hammering frequency $\mathrm{F}=200 \mathrm{~Hz}$ ).

Because of this distance it was possible to measure the resulting indentation depth depending on a variation of different peening distances $t$, used to machine the single impact lines (example of depth measurement shown in Fig. 5).

As it can be shown the final depth of the produced indentations can be influenced significantly by a variation of the peening distance $t$. Fig. 5 is illustrating this relationship in the form of a table, which is showing that the indentation depth is increasing by increasing distance $t$. This result suggests that there has to be a direct relationship between the peening distance and the impact energy of the peening tool.

Facing the fact that a number of tools with different sphere diameter, which is determining the ratio between indentation depth and it's width, can be used to modify the surface, MHP opens up a wide range of opportunities in defined surface structuring only by varying the process parameters.

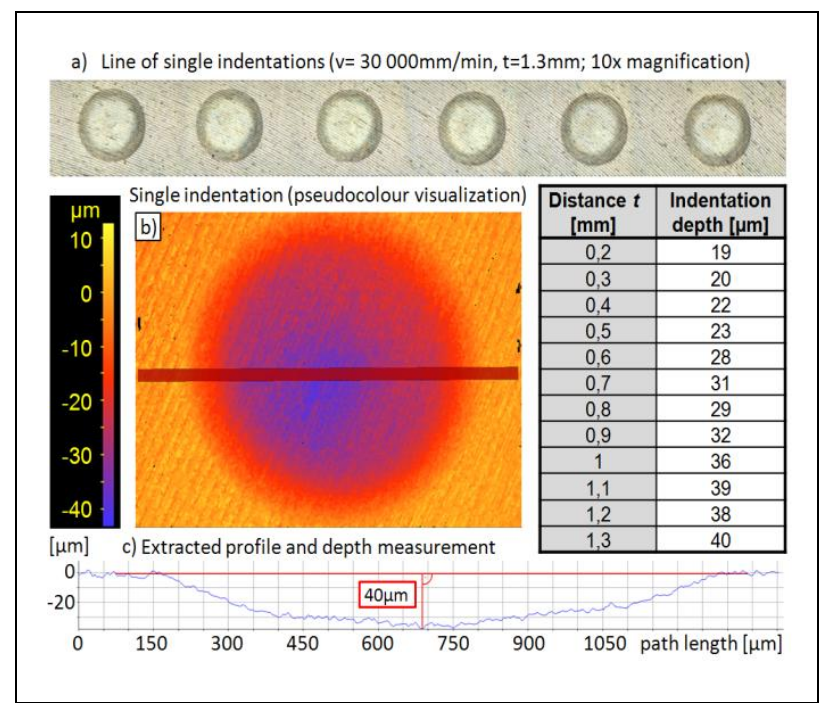

Fig. 5.Depth measurement of single indentations created by using varying peening distances $t$ : a) Infinite Focus (Alicona) surface topography measurement of the single indentation line $t=1,3 \mathrm{~mm} b$ ) Single indentation $(t=1,3 \mathrm{~mm})$ illustrated in pseudo colours $\mathrm{c})$ Depth measurement of indentation $\mathrm{t}=1,3 \mathrm{~mm}$

\section{DEFINED SURFACE MICRO STRUCTURING}

\subsection{Approach}

As an approach to structure a materials surface with complex geometries by the use of the MHP-technology, the negative form of a finally desired surface structure was machined on the plunger tip. If this tool is further used during the MHP-process, it could be expected to stamp the structure onto the materials surface.

First experiments with different structures, presented in the following, have been conducted in order to prove the possibility of such defined micro structuring using MHP. Therefore the aluminium alloy EN AW-6060 (AlMgSi05, 3.3206) was used as comparatively soft workpiece material.

If the fundamental suitability of the method can be proven, further experiments using steel samples will be done.

\subsection{Method}

In order to design the tools used in the experiments a 3D micro EDM (Electric Discharge Machining) milling machine SX-200 (Sarix) was used. This machine enables micromachining of conductive workpieces to produce complex designs while ensuring very tight tolerances.

The negative forms of the structures have been designed by the use of the CAD software SolidWorks and then been directly imported into the CAM module of the micro EDM milling machine. In this way a high precision positioning of the electrode and therewith high precision of the workpiece could be ensured.

For the present study two plungers with different shaped tips have been produced.

For a first experiment a peening tool with sphere diameter of $5 \mathrm{~mm}$ was flattened on its tip so that a flat circular surface of $0.6 \mathrm{~mm}$ diameter was resulting. In a second step a concave equilateral triangle of side length $0.2 \mathrm{~mm}$ was machined into this surface. The final depth of the generated triangle has been $0.03 \mathrm{~mm}$ after electric discharge machining. In Fig. 7a the result of the EDM structuring can be seen.

In order to investigate the opportunities and limits of the presented method in structuring small dimensions, a second plunger with a spherical tool tip of $8 \mathrm{~mm}$ diameter was prepared. The tip of this plunger has been flattened, too. After that the smallest available EDM electrode was used to machine a number of single holes with $40 \mu \mathrm{m}$ diameter and a depth of $55 \mu \mathrm{m}$ into the flatted tip.

Fig. 6 shows a microscope image of the resulting square field of holes which have a distance of $60 \mu \mathrm{m}$ between each other. Further an Infinite Focus topography measurement of four of these holes illustrated in pseudo colours can be seen in this figure. These two modified peening tools have than been used in a number of experiments in which the parameters of the MHP-process have been arranged in different ways. 


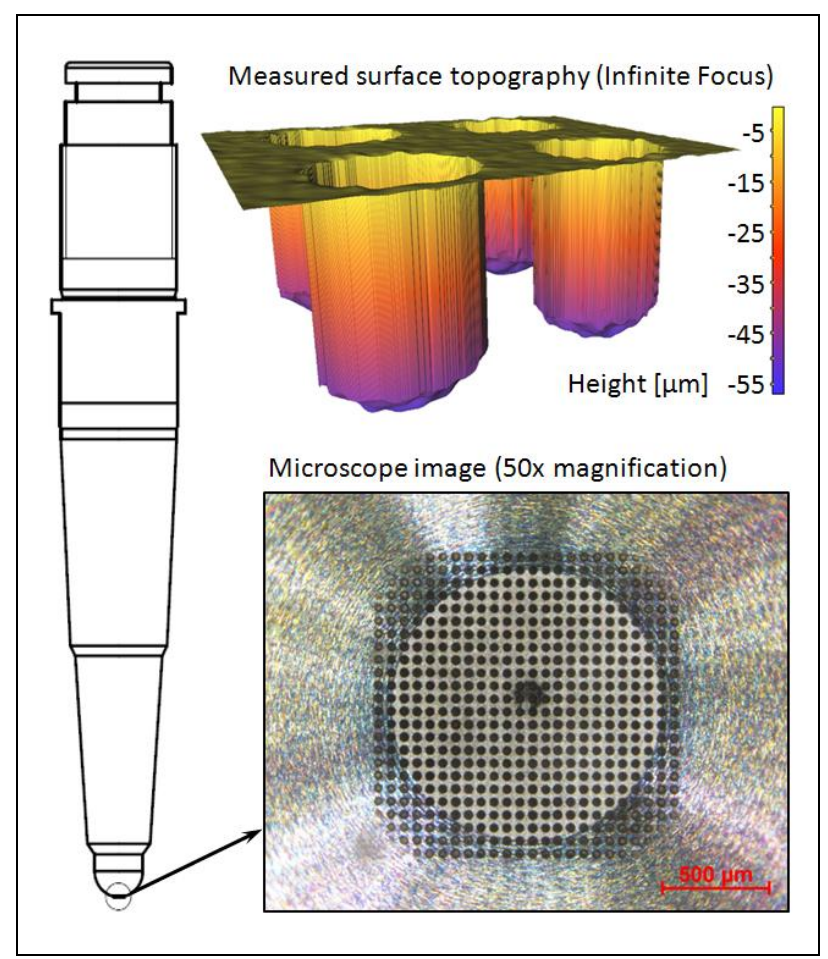

Fig. 6. Shaped plunger tip (single holes)

Different feed rates, peening frequencies and line pitches as well as different impact energies (mainly depending on the peening distance $t$ ) have been tested.

The influence of the different parameter settings on the resulting surface structure have been assessed on an ongoing basis using the stereomicroscope SMZ 1500 (Nikon).

The optimized structuring results have further been evaluated by the use of Infinite Focus (Alicona) surface topography measurements and are presented in the following.

\subsection{Experimental results}

As it could be shown, it was possible to structure the surface of the investigated aluminium alloy material by the use of MHP and functionally formed peening tools.

During the experiments triangles as well as defined asperities with cylindrical basic shape, resulting from the plunger tip modified with single holes, could be generated.

In Fig. $7 \mathrm{~b}$ the surface structured with equilateral triangles can be seen.

\begin{tabular}{|l|c|c|}
\hline \multirow{2}{*}{ Parameter } & \multicolumn{2}{|c|}{ MHP- parameters (triangle plunger) } \\
\cline { 2 - 3 } & Unit & Value \\
\hline Diameter $D$ & $\mathrm{~mm}$ & 5 (structured with triangle) \\
\hline Line pitch $s$ & $\mathrm{~mm}$ & 0.5 \\
\hline Frequency $F$ & $\mathrm{~Hz}$ & 200 \\
\hline Feed rate $v$ & $\mathrm{~mm} / \mathrm{min}$ & 6000 \\
\hline Distance $f$ & $\mathrm{~mm}$ & 0.5 \\
\hline
\end{tabular}

Tab. 2. Used parameter setting for structuring the surface illustrated in Fig. 7b

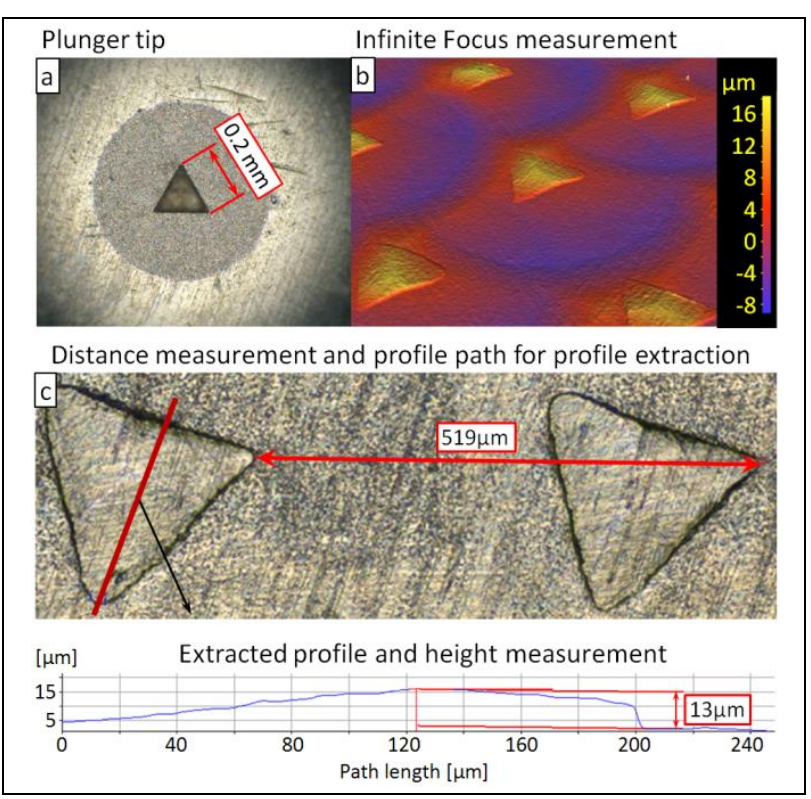

Fig. 7. Surface structuring: a) Shaped plunger tip (SMZ 1500 microscope image) b) Infinite Focus surface topography measurement of the structured surface (20x magnifications) visualized in pseudo colours. c) Measurement of distance and height (Infinite Focus, 20x magnification)

The MHP parameters used to machine this surface are given in Tab. 2.

The triangles stamped on the surface have a maximum height of approximately $13 \mu \mathrm{m}$. The distance between the triangles correlates very accurately to the chosen line pitch of $\mathrm{s}=0.5 \mathrm{~mm}$ and the distance $f$ of also $0.5 \mathrm{~mm}$ (Fig. 7c).

Also in the course of the further investigation, by the use of the plunger shaped with holes, a surface structuring could be achieved. Fig. 8 is presenting the resulting surface topography which could be realized by the parameter setting given in Tab. 3 .

The resulting cylindrical structures have a diameter of nearly $40 \mu \mathrm{m}$ and a maximum height of about $20 \mu \mathrm{m}$, which can be measured on some parts of the structure.

This dimensions of the resulting structures could be measured on different parts of the machined area, so that it can be pointed out that the structuring result is very uniform across the whole surface.

In summery it can be noticed that the used method seems to be suitable for defined structuring of the investigated aluminium material even in order to machine small dimensions in a $\mu \mathrm{m}$ range.

\begin{tabular}{|l|c|c|}
\hline \multirow{2}{*}{ Parameter } & \multicolumn{2}{|c|}{ MHP- parameters (hole plunger) } \\
\cline { 2 - 3 } & Unit & Value \\
\hline Diameter $D$ & $\mathrm{~mm}$ & 8 (structured with holes) \\
\hline Line pitch $s$ & $\mathrm{~mm}$ & 1 \\
\hline Frequency $F$ & $\mathrm{~Hz}$ & 200 \\
\hline Feed rate $v$ & $\mathrm{~mm} / \mathrm{min}$ & 7200 \\
\hline Distance $f$ & $\mathrm{~mm}$ & 0.6 \\
\hline
\end{tabular}

Tab. 3. Used parameter setting for structuring the surface illustrated in Fig. 8 


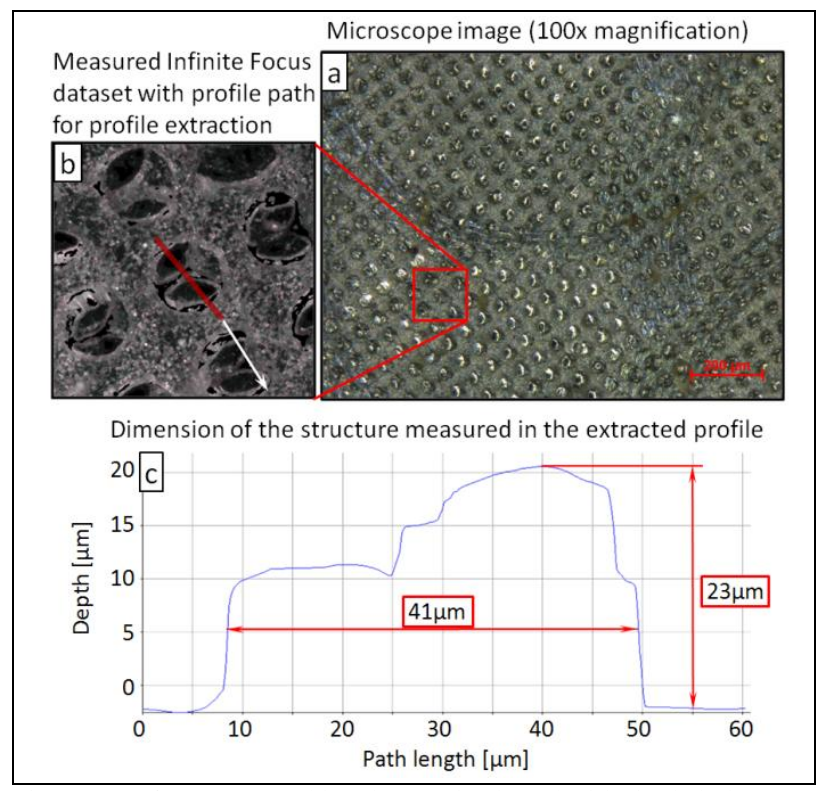

Fig. 8. Surface structured by plunger tip shaped with single holes: a) SMZ 1500 microscope image of the structured surface (100x magnification) b) Measured surface topography (Infinite Focus) c) Measurement of structure dimensions (Infinite Focus)

\section{CONCLUSIOS AND FUTURE DIRECTIONS}

The technology of Machine Hammer Peening opens up new opportunities for the modification of materials surfaces in the field of production engineering and further meets the requirements of the original process application of surface smoothening.

A significant roughness reduction of a $\mathrm{C} 45 \mathrm{E}$ steel materials surface after the Machine Hammer Peening treatment could be presented as part of this work.

The influence of two process parameters on the smoothening result was demonstrated. Beside surface roughness measurements (chapter 3) also surface topography measurements, presented as part of chapter 4, lead to the conclusion, that a small impact distance is required for optimized surface smoothening. A tool with large sphere diameter should further be used to improve the result.

Beside the investigation of the surface smoothening effect, the opportunity of a defined influencing of the surface topography by a variation of several process parameters was investigated. The wide range of possible structures as well as the accuracy of the process in order of defined and well placed impacts was shown based on examples.

In further experiments the influence of certain topographies on the tribological properties of the surface will be studied. Especially surfaces structured with single spherical indentations, which are known (as for example presented in [7]) to show high potential for friction and wear reduction in tribological systems, will be part of deeper investigations.

These investigations can be based on the results presented in chapter 4, where it was shown, that the indentation depth is significantly influenced by the variation of the peening distance $t$.
Beside the surface structuring with ordinary spherical tools the use of functionally formed peening tools is opening up an even wider range of opportunities and possible applications for the Machine Hammer Peening technology.

As part of this work, the fundamental suitability of this method for aluminium surfaces was presented. It could be shown, that it is possible to machine the negative form of a desired structure on the plunger tip and stamp it on the treated material. In this way a wanted structure in a $\mu \mathrm{m}$ range, which is uniform across the whole machined surface, can be obtained.

Based on these results, future research will be done by conducting further experiments using steel as workpiece material.

\section{ACKNOWLEDGEMENT}

This work was funded from the Austrian COMETProgram and has been carried out within the "Institute for Production Engineering and Laser Technology" in cooperation with the "Excellence Centre of Tribology", the "Institute for Energy Systems and Thermodynamics" and the "Institute of Materials Science and Technology".

The authors thank the following companies for their support in the mentioned research project (in alphabetical order): "ANDRITZ HYDRO GmbH", "EMO ORODJARNA proizvodna Druzba d.o.o.", "Flowserve Austria GmbH", "KWL - Konstruktion \& Werkzeugbau Löcker", "Maschinenfabrik Berthold Hermle AG", "Schoeller Bleckmann Oilfield Technology GesmbH", "TIWAG Tiroler Wasserkraft AG", "VERBUND AG", "Voith Hydro GmbH \& Co KG", "Vorarlberger Illwerke AG" and "Wittner Ernst GmbH".

\section{REFERENCES}

[1] http://accurapuls.de/Verfahrensbeschreibung\%20_englisch.html, (2010). Website accurapuls GmbH, Accessed on: 2012-07-02

[2] Wied, J. (2006). Machine polishing of Metal Forming Dies, Master's theses, Royal Institute of Technology, Stockholm Sweden

[3] Groche, P., Steitz, M. (2011). Prozesskettenverkürzung im Werkzeugbau, VDI-Z, Ausgabe III, 2011, pp. 22-25

[4] Wied, J. (2011). Oberflächenbehandlung von Umformwerkzeugen durch Festklopfen, Ph.D. Dissertation, Technical University of Darmstadt, Darmstadt, Germany

[5] Berglund, J.; Liljengren, M. \& Rosén, B.-G. (2011). On finishing of pressing die surfaces using machine hammer peening, International Journal of Advanced Manufacturing Technology, Vol. 52, 2011, pp. 115-121

[6] Bleicher, F.; Lechner, C.; Habersohn, C.; Kozeschnik, E.; Adjassoho, B. \& Kaminski, H. (2012). Mechanism of surface modification using machine hammer peening technology, CIRP Annals - Manufacturing Technology, Vol. 61, No. 1, pp. 375-378

[7] Schubert, A.; Neugebauer, R.; Sylla, D.; Avila, M. \& Hackert, M. (2010). Fertigungs- und Oberflächentechnologien für anforderungsgerechte, tribologische effiziente Oberflächen von Umformwerkzeugen und Powertrain- Bauteilen, Proceedings of Internationales Kolloqzium des Spitzentechnologiexlusters eniPROD<1, Chemniz, ISBN: 978-3-942267-00-7, Neugebauer, R. (Ed.), pp. 461-482, Verlag Wissenschaftliche Scripten, Zwickau 